\title{
Evaluation of Packed-Bed Reactor and Continuous Stirred Tank Reactor for the Production of Colchicine Derivatives
}

\author{
Kashyap Kumar Dubey, ${ }^{1}$ Dhirendra Kumar, ${ }^{1}$ Punit Kumar, ${ }^{1}$ \\ Shafiul Haque, ${ }^{2}$ and Arshad Jawed ${ }^{3}$ \\ ${ }^{1}$ Industrial Biotechnology Laboratory, University Institute of Engineering \& Technology, M.D. University, Rohtak, \\ Haryana 124001, India \\ ${ }^{2}$ Gene Expression Laboratory, Department of Biosciences, Jamia Millia Islamia (A Central University), New Delhi, India \\ ${ }^{3}$ RFCL, Okhla, New Delhi, India \\ Correspondence should be addressed to Kashyap Kumar Dubey; kashyapdubey@yahoo.com
}

Received 6 June 2013; Accepted 1 August 2013

Academic Editors: G. Bayramoglu, A. Brucato, I. Poulios, and I. Suelves

Copyright (C) 2013 Kashyap Kumar Dubey et al. This is an open access article distributed under the Creative Commons Attribution License, which permits unrestricted use, distribution, and reproduction in any medium, provided the original work is properly cited.

\begin{abstract}
Bioconversion of colchicine into its pharmacologically active derivative 3-demethylated colchicine (3-DMC) mediated by P450BM3 enzyme is an economic and promising strategy for the production of this inexpensive and potent anticancer drug. Continuous stirred tank reactor (CSTR) and packed-bed reactor (PBR) of $3 \mathrm{~L}$ and $2 \mathrm{~L}$ total volumes were compared for the production of 3-demethylated colchicine (3-DMC) a colchicine derivative using Bacillus megaterium MTCC*420 under aerobic conditions. Statistical optimization technique was utilized with the most significant variables, that is, dissolved oxygen (DO), colchicine concentration, and process time for optimization. The validation of the model was performed by experiments on the predicted values in an individual run, and the optimum parameters were DO $(\sim 50 \%)$, colchicine concentration $(7.5 \mathrm{~g} / \mathrm{L})$, and process time $(39 \mathrm{~h})$ resulted in a maximum bioconversion of 3-DMC $3.36 \mathrm{~g} / \mathrm{L}$. The PBR reactor achieved much higher productivity $(6.58 \mathrm{~g} / \mathrm{L} / \mathrm{h})$ as reported by earlier researchers. This is the first report on the use of PBR for bioconversion of colchicine.
\end{abstract}

\section{Introduction}

Bioreactor design is of crucial importance in the development of bioprocesses. Once a microorganism is selected and the culture and/or production conditions are optimized at laboratory scale, the next issue is proceeding to larger scale so that bulk quantities of the desired product can be produced optimally in a cost-effective manner. The selection of a proper reactor type is critical to such processes and plays a major role in large-scale production. The bioreactors widely used in today's fermentation industry are mainly those developed in the past decades purely for chemical reactions $[1,2]$. Among others, Stirred Tank Reactors (STRs) and Packed-Bed Reactors (PBRs) find the widest application. The application of these reactors for biological processes has been intensively studied with aerobic cultures [3-5].

Colchicine is a well-documented pseudo alkaloid obtained from Colchicum autumnale L. and Gloriosa superba, widely used in therapy for the treatment of gout pain persisting for a very long time $[6,7]$. It is too toxic to be of value as an antitumor drug, in its native form. Derivatives of colchicine, that is, 3-demethylcolchicine, colchicoside, and thiocolchicoside with improved therapeutic properties for anti-inflammatory and anti-tumor drugs, have good commercial demand as these compounds are known to have clinical significance for the treatment of certain forms of leukemia and solid tumors $[8,9]$. Colchicine and a number of its prepared derivatives cannot be used as such due to their high toxicity in terms of high-risk/benefit ratio [8]. As far as the use in the anti-inflammatory field is concerned, the only marketed colchicine derivative is thiocolchicoside, bearing a thiomethyl moiety at C-10 and a glucose molecule at the hydroxyl in C-10. The therapeutically uses of this derivative are related to the muscle relaxant and antiphlogistic effects $[7,10]$. Demethylated colchicine at C-3 position of the ring-A shows about 35 -fold less toxicity as compared to parent molecule, and it equally has good anti-tumor activity as compared to that of thiocolchicine. 3-demethylcolchicine 
and its glycosides are present in small amount in the colchicine producing plants [8-10].

In a rule of thumb, the classical method for determining optimal production conditions in fermentation process is varying in one process parameter while keeping others at a constant level. This practice is time-consuming and generates a need for large number of experiments, and the results are not so accurate and reproducible. In such practice, interaction effect between the variables is not taken into consideration. In recent times, response surface methodology (RSM) a good statistical experimental design tool has proved its worth, and it is now commonly used in optimization experiments of fermentation processes using biological system [11, 12]. In the present work, we have employed RSM to provide a fast and efficient way to understand and identify the significant process variables, thereby saving time and maintaining key information on each component. RSM includes factorial design and regression analysis that helps in evaluating significant variables and plotting them simultaneously against each other to evaluate the interaction and effect on each other simultaneously.

In the present work, we investigated the demethylation of colchicine in a continuous-flow packed-bed reactor in an effort to better understand possible adverse effect of colchicine bioconversion associated with the use of stirred tank reactors. When this experiment was carried out in a packed-bed reactor, the dissolved oxygen was required to be $60 \% \mathrm{v} / \mathrm{v}$ prior to entering the reactor. Because of the necessity of controlling dissolved oxygen and $\mathrm{pH}$ and making the process smoother and homogeneous, another fermenter was used to control conditions for the dissolved oxygen and other parameters. It is highly desirable to employ reaction conditions that minimize undesired secondary reactions of the indicated types. Tubular packed-bed reactors offer a number of advantages with higher conversion per unit mass of catalyst, recyclability, continuous operation, and minimum product inhibition when compared to stirred tank reactors.

\section{Materials and Methods}

2.1. Strain and Culture Medium. Bacillus megaterium MTCC $^{*} 420$ obtained from MTCC Chandigarh was used in this study. Culture methods and analytical methods were the same as previously reported by Dubey et al. $[13,14]$.

\subsection{Fermentation Conditions}

2.2.1. At Shake Flask Level. Shake flask experiments were carried out using $100 \mathrm{~mL}$ and $250 \mathrm{~mL}$ Erlenmeyer flasks containing $15 \mathrm{~mL}$ and $25 \mathrm{~mL}$ medium having $7 \mathrm{~g} / \mathrm{L}$ colchicine respectively. After inoculation, flasks were incubated over night at $28^{\circ} \mathrm{C}, 200 \mathrm{rpm}$.

The culture was incubated for $72 \mathrm{~h}$ in the same conditions as described above, and every $12 \mathrm{~h}$, samples were taken to evaluate the growth level and the 3-DMC production by HPLC $[11,15]$.

2.2.2. At Stirred Tank Reactor. All the fermenter operational conditions optimization trials were carried out in
$5 \mathrm{~L}$ fermenter (Sartorious Inc., Germany) for bioconversion experiments [13]. The working volume of fermenters was $3 \mathrm{~L}$. The impeller was 6-bladed Rushton turbine type having diameter $50 \mathrm{~mm}$ in $5 \mathrm{~L}$ fermenter. The $\mathrm{pH}$ was maintained in the fermenter by using peristaltic pump attached with $60 \%$ sugar solution. The cultivation time for growth was $72 \mathrm{~h}$. Operational conditions were employed as reported by Dubey et al. [13].

2.2.3. Apparatus Used for Packed-Bed Reactor. The packedbed reactor consisted of $20 \mathrm{~cm}$ of tubing $(2.5 \mathrm{~cm}$ i.d.) containing $25 \mathrm{~g}$ of immobilized $B$. megaterium cells. The tubing was packed manually with the dry immobilized cells. The packing was then fixed in place using a mesh connected to stainless steel plugs. This tubing was submerged in a constant temperature water bath. A syringe pump was used to supply the colchicine.

Prior to initiating flow of colchicine to the reactor, nitrogen was passed through the packed bed for $5 \mathrm{~min}$ to remove air. Each experiment was initiated by quickly flushing the reactor with a total volume of the mixture of substrates equal to at least twice the void volume of the reactor. After quasi-steady-state operating conditions were achieved, several samples of the effluent stream were manually collected over a time frame corresponding to at least three reactor space times. (The reactor space time is the ratio of the void volume of the reactor to the total volumetric flow rate of the two feed stocks.) For a set of experiments corresponding to a specified operating temperature, the experiments at different space times were conducted in random order.

\subsubsection{Determination of the Void Volume and the Space Time.} The void volume $\left(1.3 \mathrm{~cm}^{3} / \mathrm{g}\right.$ of catalyst) was calculated using the difference between the weights of the packed-bed reactor (tubing+catalyst) when filled with a colchicine of known density and the corresponding weight of the packed-bed reactor in the absence of this fluid. Corrections were made for the regions of the tubing outside the packed bed. Reactor space times were calculated as the ratio of the void volume of the reactor to the total volumetric flow rate of the two feedstocks.

2.3. Statistical Analysis. The optimization experiments were statistically designed and performed using response surface methodology (RSM) using Design-Expert from StatEase, Inc. DO concentration, substrate concentration, and process time were considered as important variables in the experimental design and had been considered for optimization. The other process components were kept at constant levels throughout the experimental runs. The parameters, for example, DO, substrate conc., and process time, were simultaneously varied as depicted in Table 1 . The results for substrate conversion were fed in the responses against each run (shown in Table 1). The experiments were designed according to the statistical design software Design-Expert 8.0 from Stat-Ease Inc. (Trial version).

The obtained data in real time was added in each set corresponding to the individual experiments. Design expert uses statistical designs and tools for predicting the significance and 


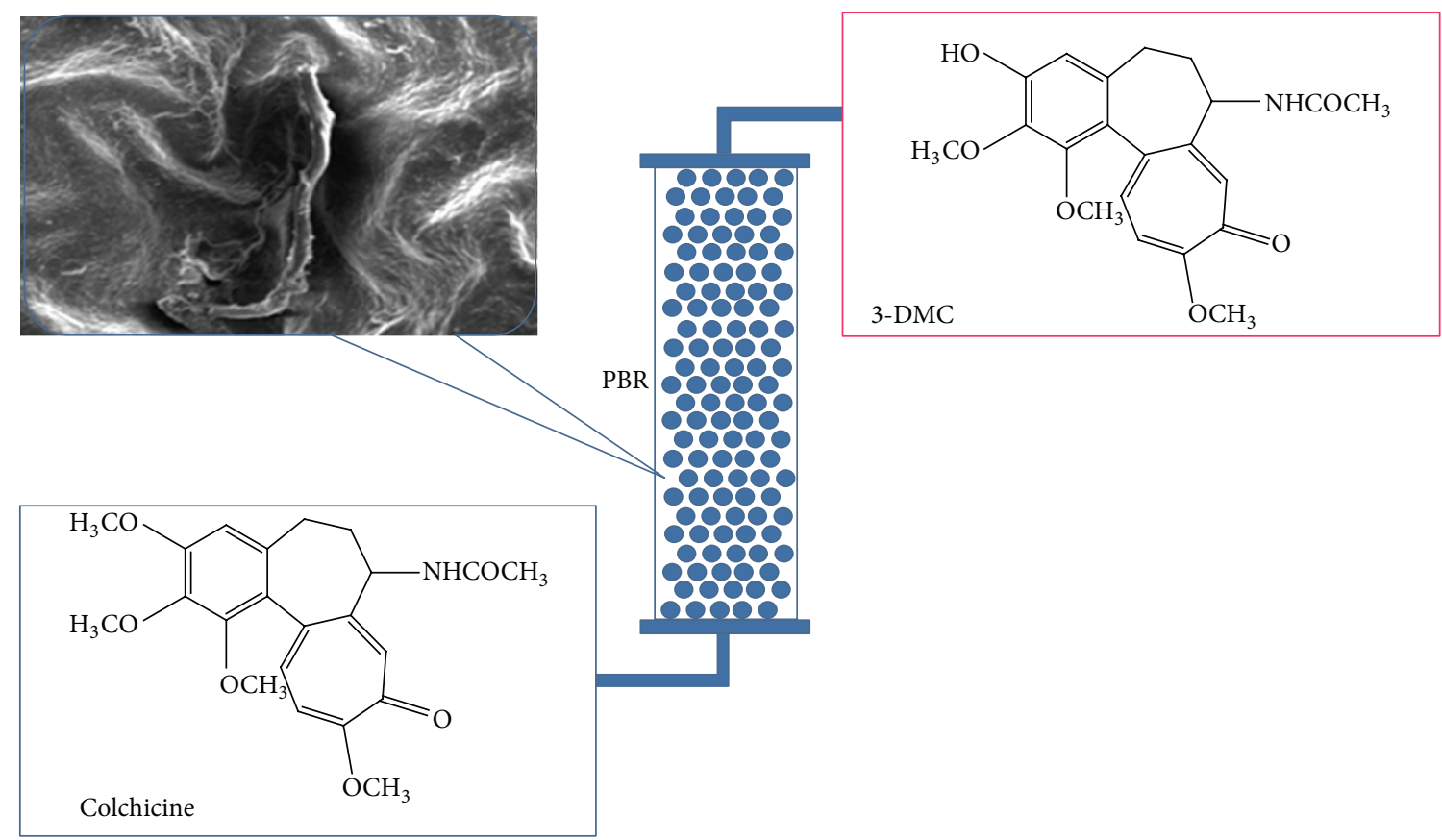

FIGURE 1: Schematic diagram showing biocatalysis process for conversion of colchicine to 3-demethylated colchicine through packed-bed reactor (PBR).

accuracy of the model as well as the predicted trends, in the attempted design space. The results were fitted into various RSM models out of which central composite design (CCD) predicted curves with better regression coefficients and nonsignificant lack of fit. Table 2 shows the maximum, minimum, central, and $\alpha$ value for dissolved oxygen, colchicine concentration, and process time, respectively. Data analysis was carried out using Design Expert software (free-trial version).

\section{Results and Discussion}

The present study, performed for the possible application of PBR system in biotransformed products. Previous researchers have published various research articles on the use of PBR system for biotransformation [16-18]. Author has also published report on submerged fermentation through Bacillus megaterium acting as biocatalyst for colchicine bioconversion [11-14]. In view of the facts and the demand of marketing, this study was performed to define a suitable reactor system which has less shear stress during biocatalysis mechanism. Earlier studies were carried out with CSTR with low productivity. In the current paper, we analyzed various important process parameters with special emphasis on dissolved oxygen, substrate concentration, and process time using statistical techniques for process optimization and control.

Our previous reports on bioconversion of colchicine, $B$. megaterium was successfully exploited for biotransformation, and effects of different concentrations ( $5 \mathrm{mM}$ to $35 \mathrm{mM}$ ) of substrate/product (colchicine/3-DMC) toxicity on growth rate of $B$. megaterium have been studied [14] in CSTR. The similar results were achieved in PBR system with 2-3\% variation (data not shown).
TABLE 1: Design matrix generated by DoE showing response of each run.

\begin{tabular}{lcccc}
\hline Run & $\begin{array}{c}\text { A } \\
\text { Dissolved } \\
\text { oxygen } \\
(\%)\end{array}$ & $\begin{array}{c}\text { B } \\
\text { Colchicine } \\
(\mathrm{g} / \mathrm{L})\end{array}$ & $\begin{array}{c}\text { C } \\
\text { Process time } \\
(\mathrm{h})\end{array}$ & $\begin{array}{c}\text { Predicted } \\
\text { 3-DMC } \\
(\mathrm{g} / \mathrm{L})\end{array}$ \\
\hline 1 & 50.00 & 5.00 & 48.00 & 4.32 \\
2 & 32.50 & 7.50 & 39.00 & 4.60 \\
3 & 32.50 & 7.50 & 39.00 & 4.60 \\
4 & 15.00 & 5.00 & 48.00 & 1.45 \\
5 & 32.50 & 7.50 & 39.00 & 4.60 \\
6 & 32.50 & 7.50 & 39.00 & 4.60 \\
7 & 32.50 & 11.70 & 39.00 & 3.18 \\
8 & 32.50 & 7.50 & 39.00 & 4.60 \\
9 & 32.50 & 7.50 & 39.00 & 4.60 \\
10 & 50.00 & 10.00 & 30.00 & 4.60 \\
11 & 32.50 & 7.50 & 54.14 & 5.10 \\
12 & 15.00 & 10.00 & 48.00 & 2.74 \\
13 & 50.00 & 10.00 & 48.00 & 7.90 \\
14 & 32.50 & 3.30 & 39.00 & 2.43 \\
15 & 61.93 & 7.50 & 39.00 & 5.95 \\
16 & 15.00 & 10.00 & 30.00 & 0.91 \\
17 & 15.00 & 5.00 & 30.00 & 1.12 \\
18 & 3.07 & 7.50 & 39.00 & 0.67 \\
19 & 32.50 & 7.50 & 23.86 & 2.04 \\
20 & 50.00 & 5.00 & 30.00 & 3.10 \\
\hline & & & &
\end{tabular}

Before starting the bioconversion experiments on PBR (Figure 1), the process was optimized at shake flask level 
TABLE 2: Concentration ranges of independent process variables (dissolved oxygen, colchicine concentration, and process time) used in RSM.

\begin{tabular}{lccccccccc}
\hline Factor & Name & Units & Type & Min. & Max. & -1 actual & +1 actual & Mean & Std. Dev. \\
\hline A & DO & $(\%)$ & Numeric & 3.07 & 61.93 & 15 & 50 & 32.5 & 14.46 \\
B & Colchicine & $(\mathrm{g} / \mathrm{L})$ & Numeric & 3.3 & 11.7 & 5 & 10 & 7.5 & 2.07 \\
C & Process Time & $(\mathrm{s})$ & Numeric & 31.91 & 52.09 & 36 & 48 & 42 & 4.96 \\
\hline
\end{tabular}

TABLE 3: ANOVA for response surface quadratic model to verify whether developed model is significant or nonsignificant.

\begin{tabular}{|c|c|c|c|c|c|}
\hline Source & Sum of squares & Degrees of freedom & Mean square & $F$ value & $P$ value $($ prob $>F)$ \\
\hline Model & 66.63 & 6 & 11.1 & 176.23 & $<0.0001^{*}$ \\
\hline A-DO & 45.96 & 1 & 45.96 & 729.41 & $<0.0001$ \\
\hline B-Colchicine & 13.71 & 1 & 13.71 & 217.54 & $<0.0001$ \\
\hline C-Process time & 3.37 & 1 & 3.37 & 53.51 & $<0.0001$ \\
\hline $\mathrm{AB}$ & 2.82 & 1 & 2.82 & 44.76 & $<0.0001$ \\
\hline $\mathrm{AC}$ & 0.56 & 1 & 0.56 & 8.83 & 0.0108 \\
\hline $\mathrm{BC}$ & 0.21 & 1 & 0.21 & 3.3 & 0.0923 \\
\hline Residual & 0.82 & 13 & 0.063 & & \\
\hline Lack of fit ${ }^{* *}$ & 0.82 & 8 & 0.1 & & \\
\hline
\end{tabular}

${ }^{*}$ significant, ${ }^{* *}$ nonsignificant.

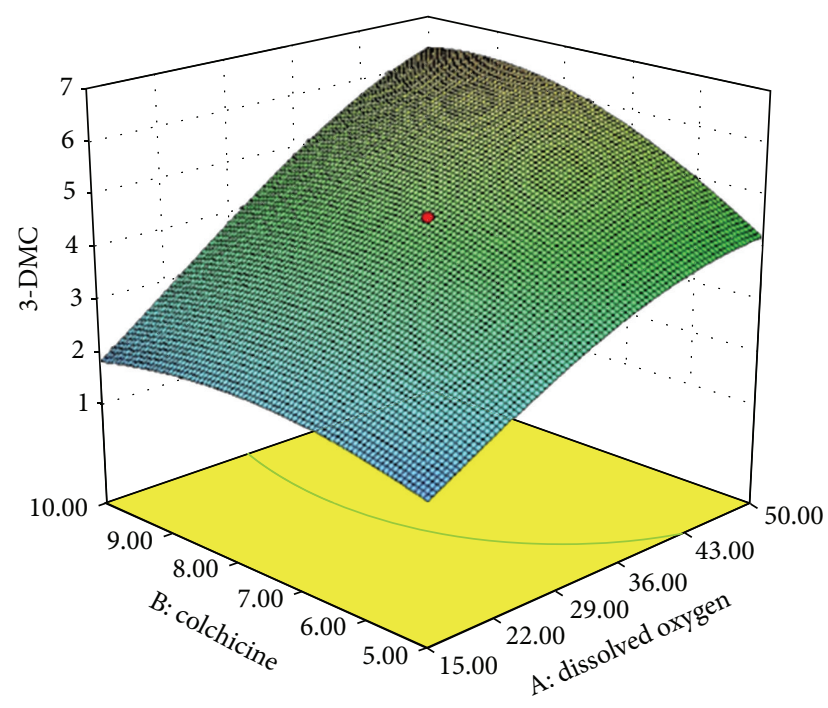

FIGURE 2: Response surface methodology showing bioconversion of colchicine to $3 \mathrm{DMC}$ with response to dissolved oxygen (DO).

which was carried forward to PBR system. In this study, various parameters were considered and were attempted for optimization by classical approach. The first step was to optimize the initial substrate concentration, within the selected range of $3 \mathrm{~g} / \mathrm{L}$ to $10 \mathrm{~g} / \mathrm{L}$ colchicine. The shake flasks were added with colchicine in an increment of $1 \mathrm{~g} / \mathrm{L}$ colchicine at $0 \mathrm{~h}$ of the process. The incubation was done at $28^{\circ} \mathrm{C}$ for $72 \mathrm{~h}$.

\subsection{CSTR versus $P B R$}

3.1.1. Response Surface Analysis for Optimization of Bioconversion Parameter. The optimization of bioconversion parameter was analyzed by response surface methodology. Table 1 represents the design matrix of the variables (DO, substrate conc., process time) in coded units along with the 3-DMC yield in $\mathrm{mg} / \mathrm{L}$. Table 3 shows the least square fit and significance of regression coefficient of variable parameter individually and in combination. The level of significance of each of the coefficient was checked by its respective $P$ value to confirm the interaction between the tested variables. It was noticed that with the decrease of the magnitude of the $P$-value, the corresponding coefficient was in increasing tendency. This result was in confirmation with the earlier findings by Dubey et al. $[10,14]$. From the response surface data analysis, that the empirical relationship between 3-DMC yield $(\mathrm{mg} / \mathrm{L})$ and the tested variables $\left(X_{i}\right)$ in the coded units through the following regression equation was confirmed:

$$
\begin{aligned}
3-\mathrm{DMC}(\mathrm{g} / \mathrm{L})= & 3.36+1.83+{ }^{*} \mathrm{~A}+\mathrm{B} \\
& +0.5^{*} \mathrm{C}+0.59^{*} \mathrm{~A}^{*} \mathrm{~B} \\
& +0.26^{*} \mathrm{~A}^{*} \mathrm{C}+0.16^{*} \mathrm{~B}^{*} \mathrm{C} .
\end{aligned}
$$

The contour graphs were plotted to determine the interaction of the variables and to determine the optimum level of each variable for maximum 3-DMC recovery (Figures 2 and 3). The model predicted maximum 3-DMC yield at dissolved oxygen $40 \%$, substrate concentration (colchicine) $7.5 \mathrm{~g} / \mathrm{L}$, and process time $39 \mathrm{~min}$.

Comparison of CSTR as well as PBR was performed by taking significant parameters for the study, namely, intial cell conc. $\left(X_{0} \mathrm{~g} / \mathrm{L}\right)$, maximum cell conc. $\left(X_{m} \mathrm{~g} / \mathrm{L}\right)$, and Initial colchicine conc. $\left(S_{0} \mathrm{mM}\right)$, productivity $(\mathrm{g} / \mathrm{L} / \mathrm{h})$ and bioconversion time (h) (Table 4 ). Table 4 shows that maximum productivity was obtained in PBR system, that is, $6.58 \mathrm{~g} / \mathrm{L} / \mathrm{h}$, in respect to earlier published reports on CSTR, that is, $4.7 \mathrm{~g} / \mathrm{L} / \mathrm{h}[13]$.

3.1.2. Reusability of Biocatalyst. On the other hand, a set of triplicate experiments were performed in which a proposed 


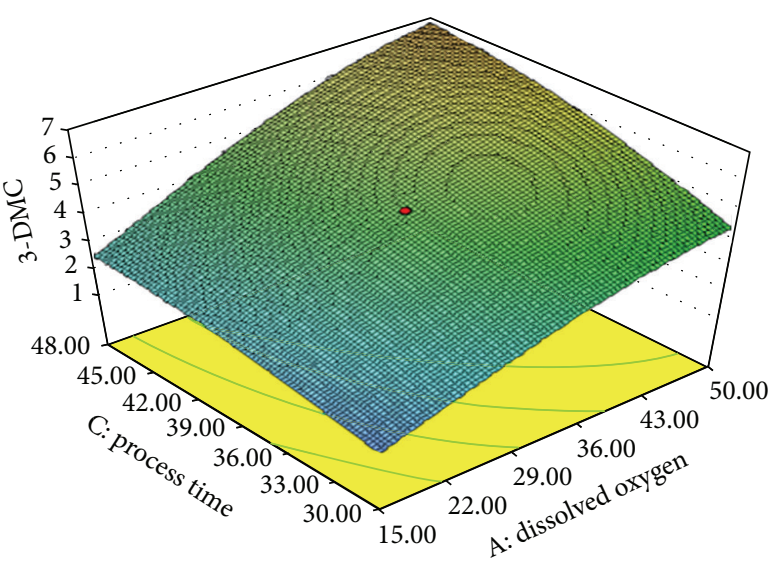

FIGURE 3: Response surface methodology showing bioconversion of $3 \mathrm{DMC}$ with response to dissolved oxygen (DO) and process time.

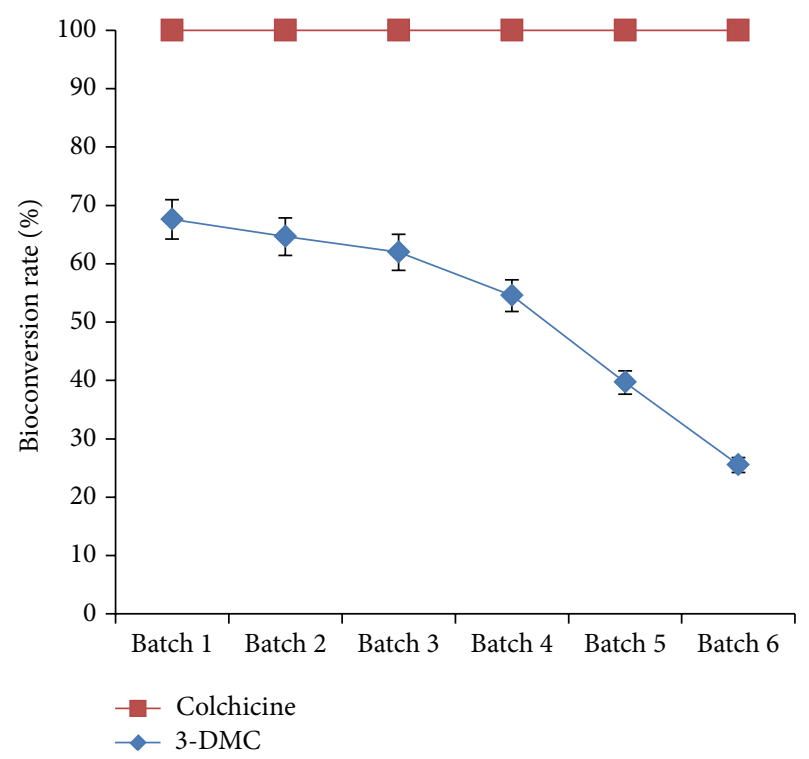

FIGURE 4: Showing batch-wise reuse of PBR system having constant flow of colchicine, that is, $35 \mathrm{mM}$ converted into 3-DMC.

PBR system worked out for bioconversion efficiency for continuous six batch experiments in which $35 \mathrm{mM}$ colchicine concentration used initially. Batch-wise experiments were performed (Figure 4 ) in which batch 1 shows $\sim 67 \%$ colchicine converted to 3 -DMC followed by $\sim 60 \%$ as batch 3 , and batch 4 , the $\sim 40 \%$ conversion rate was obtained, and very poor conversion was found at batch 6 . Results showed loosing of biocatalytic/enzymatic activity after completion of five batch experiments in PBR.

\section{Conclusion}

The results here presented comprise a new approach to the bioconversion of colchicine into their respective derivative, that is, 3-demethylated colchicine (3-DMC). Furthermore, experimental design has provided an influential tool not only to study but also in optimization of bioconversion conditions
TABLE 4: Performance comparison of STR and PBR of lab scale for the production of 3-DMC at an equal DO level.

\begin{tabular}{lcc}
\hline Parameters & CSTR & PBR \\
\hline$X_{0}(\mathrm{~g} / \mathrm{L})$ & 1.2 & 25 \\
$X_{m}(\mathrm{~g} / \mathrm{L})$ & 180 & 25 \\
$S_{0}(\mathrm{mM})$ & 35 & 35 \\
Productivity $(\mathrm{g} / \mathrm{L} / \mathrm{h})$ & $4.78[13]$ & 6.58 \\
Bioconversion time $(\mathrm{h})$ & 72 & 32 \\
\hline
\end{tabular}

(CSTR) continuous stirred tank reactor; (PBR) packed-bed reactor; $X_{0}$ : initial cell concentration; $X_{m}$ : maximum cell concentration; $S_{0}$ : initial substrate (colchicine) concentration $\mathrm{g} / \mathrm{L}$.

that allows a significant enhancement of decisive feature of this process. Scanty reports are available on the PBR as an alternative form for CSTR mainly for the cultivation of the microorganisms which are sensitive to shear stress. In the present study, experimental design has been employed to evaluate the performance of continuous PBR system designed for the attainment of high bioconversion rate. Hence proposed continuous PBR reactor illustrates highly selective 3-DMC production achieved, which is considerably higher (Table 4) than the previous reports. The stability of operational and biocatalyst established the suitability and applicability of the proposed PBR. It was understood that the activity of enzyme was not altered significantly by operations as demonstrated by reuse of the same bed for five batches. Proposed system is presently being tested in the other stereospecific compounds with pharmacological interest.

\section{Acknowledgment}

Kashyap Kumar Dubey sincerely acknowledges UIET, M.D. University, for providing the facilities for research work.

\section{References}

[1] M. A. Al-Juaied, D. Lafarga, and A. Varma, "Ethylene epoxidation in a catalytic packed-bed membrane reactor: experiments and model," Chemical Engineering Science, vol. 56, no. 2, pp. 395-402, 2001.

[2] C. F. Torres, F. Munir, L. P. Lessard, and C. G. Hill Jr., "Lipasemediated acidolysis of tristearin with CLA in a packed-bed reactor: a kinetic study," Journal of the American Oil Chemists' Society, vol. 79, no. 7, pp. 655-661, 2002.

[3] D. Chen, Z. Lewandowski, F. Roe, and P. Surapaneni, "Diffusivity of $\mathrm{Cu}^{2+}$ in calcium alginate gel beads," Biotechnology and Bioengineering, vol. 41, no. 7, pp. 755-760, 1993.

[4] A. Sánchez, F. Valero, J. Lafuente, and C. Solà, "Highly enantioselective esterification of racemic ibuprofen in a packed bed reactor using immobilised Rhizomucor miehei lipase," Enzyme and Microbial Technology, vol. 27, no. 1-2, pp. 157-166, 2000.

[5] H. Tanaka, M. Matsumura, and I. A. Veliky, "Diffusion characteristics of substrates in Ca-ALGINATE gel beads," Biotechnology and Bioengineering, vol. 26, no. 1, pp. 53-58, 1984.

[6] T. Tateishi, P. Soucek, Y. Caraco, F. Peter Gnengerich, and A. J. J. Wood, "Colchicine biotransformation by human liver microsomes," Biochemical Pharmacology, vol. 53, no. 1, pp. 111116, 1997. 
[7] M. Rösner, H.-G. Capraro, A. E. Jacobson et al., "Biological effects of modified colchicines. Improved preparation of 2-demethylcolchicine, 3-demethylcolchicine, and (+)colchicine and reassignment of the position of the double bond in dehydro-7-deacetamidocolchicines," Journal of Medicinal Chemistry, vol. 24, no. 3, pp. 257-261, 1981.

[8] A. Muzaffar, A. Brossi, C. M. Lin, and E. Hamel, "Antitubulin effects of derivatives of 3-demethylthiocolchicine, methylthio ethers of natural colchicinoids, and thioketones derived from thiocolchicine. Comparison with colchicinoids," Journal of Medicinal Chemistry, vol. 33, no. 2, pp. 567-571, 1990.

[9] P. Kerekes, P. N. Sharma, A. Brossi, C. F. Chignell, and F. R. Quinn, "Synthesis and biological effects of novel thiocolchicines. 3. Evaluation of N-acyldeacetylthiocolchicines, N-(alkoxycarbonyl) deacetylthiocolchicines, and O-ethyldemethylthiocolchicines. New synthesis of thiodemecolcine and antileukemic effects of 2-demethyl- and 3-demethylthiocolchicine," Journal of Medicinal Chemistry, vol. 28, no. 9, pp. 1204-1208, 1985.

[10] K. K. Dubey, A. Jawed, and S. Haque, "Enhanced bioconversion of colchicine to regiospecific 3-demethylated colchicine (3DMC) by whole cell immobilization of recombinant $E$. coli harboring P450 BM-3 gene," Process Biochemistry, vol. 48, pp. 1151-1158, 2013.

[11] K. K. Dubey, A. Jawed, and S. Haque, "Enhanced extraction of 3-demethylated colchicine from fermentation broth of Bacillus megaterium: optimization of process parameters by statistical experimental design," Engineering in Life Sciences, vol. 11, no. 6, pp. 598-606, 2011.

[12] K. K. Dubey and B. K. Behera, "Statistical optimization of process variables for the production of an anticancer drug (colchicine derivatives) through fermentation: at scale-up level," New Biotechnology, vol. 28, no. 1, pp. 79-85, 2011.

[13] K. K. Dubey, A. R. Ray, and B. K. Behera, "Production of demethylated colchicine through microbial transformation and scale-up process development," Process Biochemistry, vol. 43, no. 3, pp. 251-257, 2008.

[14] K. K. Dubey, S. Haque, A. Jawed, B. P. Singh, and B. K. Behera, "Construction of recombinant Escherichia coli for enhanced bioconversion of colchicine into 3-demethylated colchicine at 701 bioreactor level," Process Biochemistry, vol. 45, no. 7, pp. 1036-1042, 2010.

[15] A. E. Klein and P. J. Davis, "Determination of colchicine and colchiceine in microbial cultures by high-performance liquid chromatography," Analytical Chemistry, vol. 52, no. 14, pp. 24322435, 1980.

[16] P. Ducommun, P.-A. Ruffieux, A. Kadouri, U. Von Stockar, and I. W. Marison, "Monitoring of temperature effects on animal cell metabolism in a packed bed process," Biotechnology and Bioengineering, vol. 77, no. 7, pp. 838-842, 2002.

[17] H. Treichel, D. de Oliveira, M. A. Mazutti, M. Di Luccio, and J. V. Oliveira, "A review on microbial lipases production," Food and Bioprocess Technology, vol. 3, no. 2, pp. 182-196, 2010.

[18] X. Xu, H. Mu, C. E. Høy, and J. A. Nissen, "Production of specifically structured lipids by enzymatic interesterification in a pilot enzyme bed reactor: process optimization by response surface methodology," Lipid/Fett, vol. 101, pp. 207-214, 1999. 

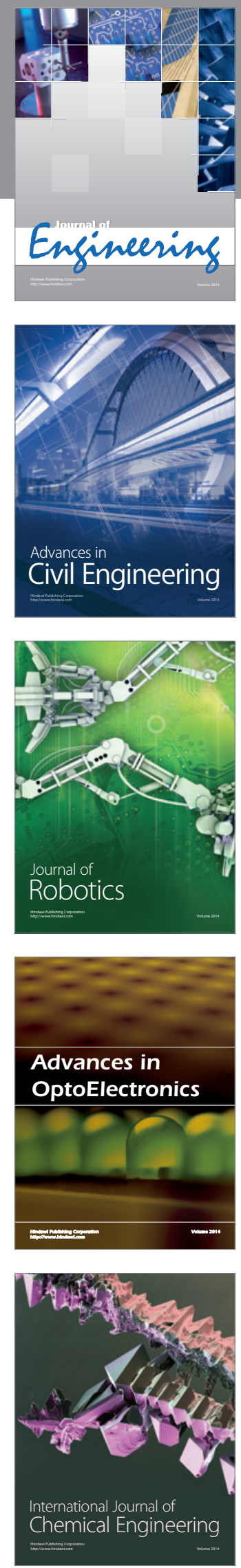

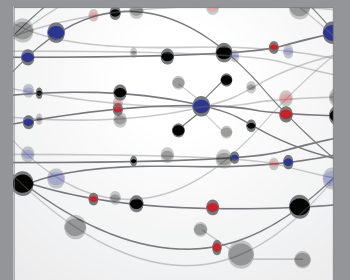

The Scientific World Journal
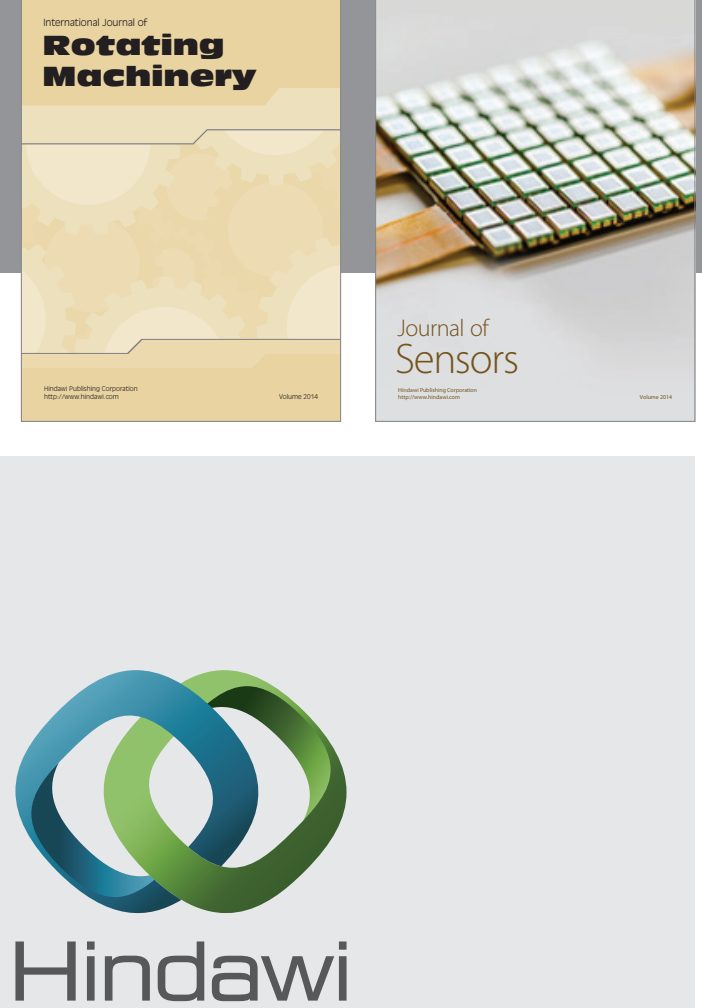

Submit your manuscripts at http://www.hindawi.com
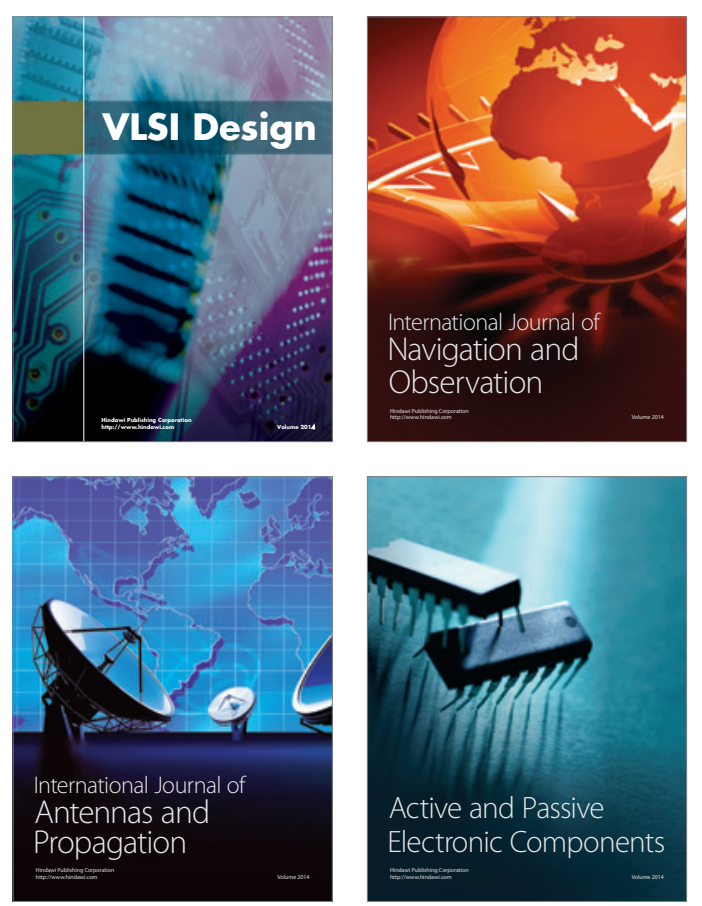
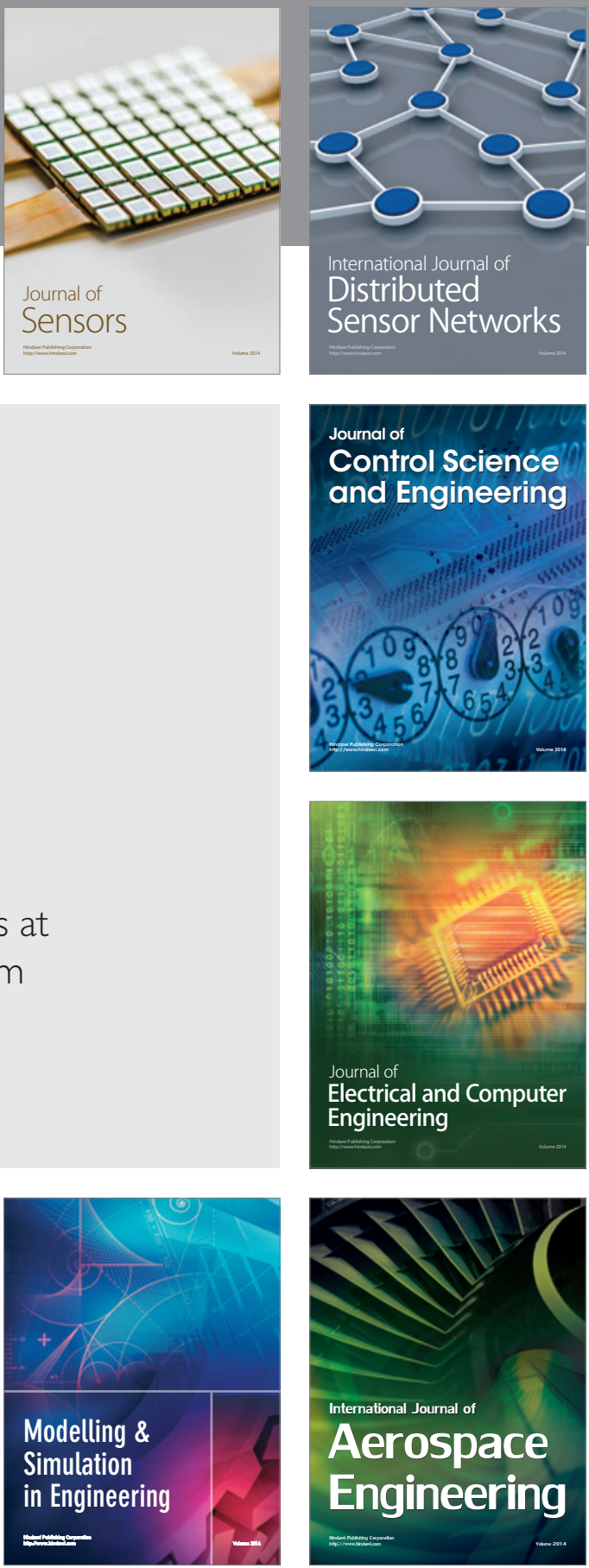

Journal of

Control Science

and Engineering
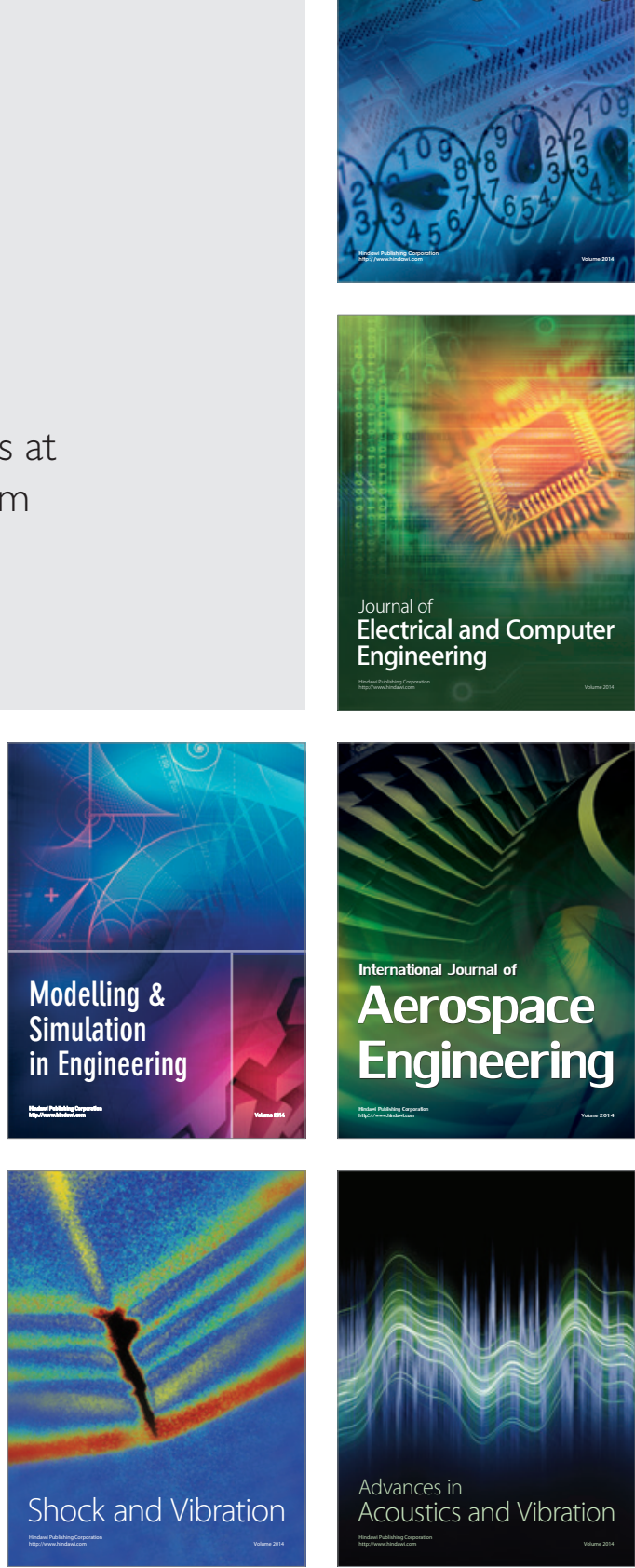